\title{
Learning to Lead: The Role of a Teacher Training Institution
}

\begin{abstract}
There is a strong belief that in order to improve classroom process as well as its outcomes, teachers' effectiveness should be enhanced. Effective leadership is the most important determinant for the effectiveness of the organization. In a classroom, a teacher assumes the leadership roles for the effectiveness of the teaching learning process. A teacher has to be an effective leader if he or she wants to bring out successful educational outcomes. To be an effective leader, a teacher has to have certain leadership characteristics. This article will discuss research findings of leadership characteristics possessed by prospective teachers trained in UPM. The findings showed that majority of the respondents felt that they possessed leadership characteristics necessary to be an effective leader.
\end{abstract}

Keyword: Teacher Trainees, Leadership Characteristics, Teacher Training Institutions 